

\title{
Some results on cordiality labeling of generalized Jahangir graph
}

\author{
R. Hasni ${ }^{\mathrm{a}}$, S. Matarneh ${ }^{\mathrm{a}}$, A. Azaizeh ${ }^{\mathrm{b}}$ \\ ${ }^{a}$ School of Informatics and Applied Mathematics, University Malaysia Terengganu, 21030 UMT, \\ Kuala Terengganu, Terengganu, Malaysia \\ ${ }^{b}$ College of Applied Sciences and Community Service, University of Dammam, KSA \\ hroslan@umt.edu.my,s_math_1985_2009@yahoo.com.my
}

\begin{abstract}
In this paper we consider the cordiality of a generalized Jahangir graph $J_{n, m}$. We give sufficient condition for $J_{n, m}$ to admit (or not admit) the prime cordial labeling, product cordial labeling and total product cordial labeling.

Keywords: Generalized Jahangir graph, Prime cordial labeling, Product cordial labeling, Total product cordial labeling Mathematics Subject Classification: 05C78, 05C38

DOI: $10.19184 /$ ijc.2017.1.2.1
\end{abstract}

\section{Introduction}

Let $G=(V, E)$ be the connected, simple and undirected graph with vertex set $V$ and edge set $E(G)$. For standard terminology and notations in Graph Theory, we refer [18]. By a labeling we mean any mapping that carries aset of graph elements to a set of numbers (usually positive integers), called labels. If the domain of the mapping is the set of vertices or the set of edges, then the labeling is called a vertex labeling or (edge labeling). If the domain is $V \cup E$ then we call the labeling as total labeling. Many labeling schemes have been introduced so far and they are well explored by many researchers. For a dynamic survey on various graph labeling problems, we refer to Gallian [3].

A labeling $f: V(G) \rightarrow\{0,1\}$ is called binary vertex labeling of $G$ and $f(v)$ is called the label of the vertex $v$ of $G$ under $f$. If for an edge $e=u v$, the induced edge labeling $f^{*}: E(G) \rightarrow\{0,1\}$

Received: 06 Jan 2017, Revised: 19 May 2017, Accepted: 26 May 2017. 
is given by $f^{*}(e)=|f(u)-f(v)|$. Then $v_{f}(i)$ is the number of vertices of $G$ having label $i$ under $f$ and $e_{f}(i)$ is the number of edges of $G$ having label $i$ under $f$, where $i=0$ or 1 .

Definition 1. A binary vertex labeling $f$ of a graph $G$ is called a cordial labeling if $\left|v_{f}(0)-v_{f}(1)\right| \leq$ 1 and $\left|e_{f}(0)-e_{f}(1)\right| \leq 1$. A graph $G$ is cordial if it admits cordial labeling.

The concept of cordial labeling was introduced by Cahit [2] as a weaker version of graceful labeling and harmonious labeling.

The notion of prime labeling was originated by Entringer and was introduced by Tout et al. [17]. Motivated by the concepts of prime labeling and cordial labeling, a new concept termed as a prime cordial labeling was introduced by Sundaram et al. [8] as follows.

Definition 2. A prime cordial labeling of a graph $G$ is a bijection $f: V(G) \rightarrow\{1,2, \ldots,|V(G)|\}$ and the induced edge function $f^{*}: V(G) \rightarrow\{1,0\}$ is defined by

$$
f^{*}(e=u v)= \begin{cases}1, & \text { if } \operatorname{gcd}(f(u), f(v))=1 \\ 0, & \text { if } \operatorname{gcd}(f(u), f(v))>1\end{cases}
$$

satisfies the condition $\left|e_{f}(0)-e_{f}(1)\right| \leq 1$. The graph admits a prime cordial labeling is called a prime cordial graph.

Many graph families proved to be prime cordial, for example see [8, 12, 13, 14].

In 2004, Sundaram et al. [9] introduced the product cordial labeling of graph.

Definition 3. Let $f: V(G) \rightarrow\{0,1\}$ be a vertex labeling of a graph $G$ that induces an edge labeling function $f^{*}: E(G) \rightarrow\{0,1\}$ such that $f^{*}(u v)=f(u) f(v)$ where $u v \in E(G)$. Then $f$ is a product cordial labeling if $\left|v_{f}(1)-v_{f}(0)\right| \leq 1$ and $\left|e_{f}(1)-e_{f}(0)\right| \leq 1$. A graph $G$ is product cordial if it admits a product cordial labeling.

In 2006, Sundaram et al. [10] introduced the notion of total product cordial labeling of graph.

Definition 4. Let $f: V(G) \rightarrow\{0,1\}$ be a vertex labeling of a graph $G$ that induces an edge labeling function $f^{*}: E(G) \rightarrow\{0,1\}$ such that $f^{*}(u v)=f(u) f(v)$ where $u v \in E(G)$. Then $f$ is a total product cordial labeling if $\left|\left(v_{f}(1)+e_{f}(1)\right)-\left(v_{f}(0)+e_{f}(0)\right)\right| \leq 1$. A graph $G$ is total product cordial if it admits a total product cordial labeling.

For more results on product cordial and total product cordial, please refer $[4,5,6,9,10,11]$.

For $n, m \geq 2$, the generalized Jahangir graph $J_{n, m}$ is a graph on $n m+1$ vertices, that is, the graph consists of a cycle $C_{m n}$ with one additional vertex which adjacent to a $m$ vertices of $C_{m n}$ at distance $n$ to each other on $C_{m n}$, see $[1,7]$. The following figure shows the graph $J_{n, m}$ for $n=3$ and $m=10$.

In this paper, we investigate prime cordial labeling, product cordial labeling and total product cordial labeling of generalized Jahangir graph $J_{n, m}$.

\section{Main Results}

In this section, we present our main results. 




Figure 1. Jahangir graph $J_{3,10}$

Lemma 2.1. The Jahangir graph $J_{2, m}, m \geq 4$ is prime cordial.

Proof. Let $J_{2, m}, m \geq 4$ be Jahangir graph with the vertex set $V\left(J_{2, m}\right)=\{v\} \cup\left\{v_{i}: 1 \leq i \leq 2 m\right\}$ and the edge set $E\left(J_{2, m}\right)=\left\{v_{i} v_{i+1}: 1 \leq i \leq 2 m-1\right\} \cup\left\{v_{2 m} v_{1}\right\} \cup\left\{v v_{2 i-1}: 1 \leq i \leq m\right\}$. Clearly that $\left|V\left(J_{2, m}\right)\right|=2 m+1$ and $\left|E\left(J_{2, m}\right)\right|=3 m$.

To show that $J_{2, m}$ is a prime cordial, we define a vertex labeling $f: V\left(J_{2, m}\right) \rightarrow\{1,2, \cdots, 2 m+$ $1\}$ in the following way:

$f(v)=2, f\left(v_{1}\right)=6, f\left(v_{2}\right)=4, f\left(v_{2 m}\right)=3, f\left(v_{2 m-1}\right)=9, f\left(v_{2 m-2}\right)=5, f\left(v_{2 m-3}\right)=7$, $f\left(v_{2 m-4}\right)=1$

$$
f\left(v_{i}\right)= \begin{cases}2(i+1), & \text { if } 3 \leq i \leq\left\lfloor\frac{2 m-1}{2}\right\rfloor \\ 4 m-2 i+1, & \text { if }\left\lfloor\frac{2 m-1}{2}\right\rfloor+1 \leq i \leq 2 m-5\end{cases}
$$

We have $\left|e_{f}(0)\right|=\left\lfloor\frac{3 m}{2}\right\rfloor$ and $\left|e_{f}(1)\right|=\left\lceil\frac{3 m}{2}\right\rceil$. Then $\left|e_{f}(0)-e_{f}(1)\right| \leq 1$. Hence, the Jahangir graph $J_{2, m}$ is prime cordial.

This completes the proof.

Theorem 2.1. The Jahangir graph $J_{n, m}, n>2, m>3$ is prime cordial.

Proof. Let $J_{n, m}, n>2, m>3$ be Jahangir graph with the vertex set $V\left(J_{n, m}\right)=\{v\} \cup\left\{v_{i}: 1 \leq i \leq\right.$ $m n\}$ and the edge set $E\left(J_{n, m}\right)=\left\{v_{i} v_{i+1}: 1 \leq i \leq m n-1\right\} \cup\left\{v_{m n} v_{1}\right\} \cup\left\{v v_{n(i-1)+1}: 1 \leq i \leq m\right\}$. Clearly that $\left|V\left(J_{n, m}\right)\right|=m n+1$ and $\left|E\left(J_{n, m}\right)\right|=n(m+1)$.

To show that $J_{n, m}$ is prime cordial, we define vertex labeling $f: V\left(J_{n, m}\right) \rightarrow\{1,2, \ldots, m n+1\}$ as follows:

$$
\begin{gathered}
f(v)=2, f\left(v_{1}\right)=6, f\left(v_{2}\right)=4, f\left(v_{m n}\right)=3 \\
f\left(v_{m n-1}\right)= \begin{cases}1, & \text { for } m, n \text { are odd } \\
9, & \text { for otherwise }\end{cases}
\end{gathered}
$$




$$
\begin{aligned}
& f\left(v_{m n-2}\right)=\left\{\begin{aligned}
5, & \text { for } m, n \text { are even } \\
& \text { or } m, n \text { are odd } \\
1, & \text { for otherwise }
\end{aligned}\right. \\
& f\left(v_{m n-3}\right)= \begin{cases}7, & \text { if } m, n \text { are even } \\
& \text { or } m, n \text { are odd } \\
5, & \text { for otherwise }\end{cases} \\
& f\left(v_{m n-4}\right)= \begin{cases}1, & \text { if } m, n \text { are even } \\
9 & \text { if } m, n \text { are odd } \\
7, & \text { for otherwise }\end{cases} \\
& f\left(v_{i}\right)= \begin{cases}2(i+1), & \text { if } 3 \leq i \leq\left\lfloor\frac{n m-1}{2}\right\rfloor \\
2 m n-2 i+1, & \text { if }\left\lfloor\frac{n m-1}{2}\right\rfloor+1 \leq i \leq m n-5 .\end{cases}
\end{aligned}
$$

We have

$$
\begin{aligned}
& \left|e_{f}(0)\right|= \begin{cases}\frac{(m(n+1)-1)}{2}, & \text { if } m \text { are even } \\
\frac{(m(n+1))}{2}, & \text { and } n \text { are odd }\end{cases} \\
& \left|e_{f}(1)\right|= \begin{cases}\frac{(m(n+1)+1)}{2}, & \text { if } m \text { are even } \\
\frac{(m(n+1))}{2}, & \text { and } n \text { are odd }\end{cases}
\end{aligned}
$$

It is easy to show that $\left|e_{f}(0)-e_{f}(1)\right| \leq 1$. Hence, the Jahangir graph $J_{n, m}$ is prime cordial. This completes the proof.

The following figure illustrates the prime cordial labeling of graph $J_{3,5}$.

Theorem 2.2. The Jahangir graph $J_{n, m}$ is product cordial with $n \geq 2, m \geq 3, m$ is odd and $n$ is even.

Proof. Let $J_{n, m}$ with $n$ is even and $n \geq 2, m$ is odd and $m \geq 3$, be Jahangir graph with the vertex set $V\left(J_{n, m}\right)=\{v\} \cup\left\{v_{i}: 1 \leq i \leq m n\right\}$ and the edge set $E\left(J_{n, m}\right)=\left\{v_{i} v_{i+1}: 1 \leq\right.$ $i \leq m n-1\} \cup\left\{v_{m n} v_{1}\right\} \cup\left\{v v_{n(i-1)+1}: 1 \leq i \leq m\right\}$. Clearly that $\left|V\left(J_{n, m}\right)\right|=m n+1$ and $\left|E\left(J_{n, m}\right)\right|=m(n+1)$. 


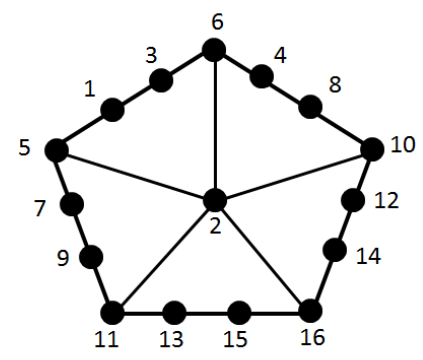

Figure 2. Prime cordial labeling of $J_{3,5}$

To show that $J_{n, m}$ is product cordial, define a vertex labeling $f: V\left(J_{n, m}\right) \rightarrow\{0,1\}$ in the following way:

$$
\begin{gathered}
f(v)=1 \\
f\left(v_{i}\right)= \begin{cases}1, & \text { if } 1 \leq i \leq \frac{n m}{2} \\
0, & \text { if } \frac{n m}{2}+1 \leq i \leq m n\end{cases}
\end{gathered}
$$

From the above labeling, we can see that $v_{f}(1)=\frac{m n+2}{2}, v_{f}(0)=\frac{m n}{2}, e_{f}(1)=\frac{m(n+1)-1}{2}$, $e_{f}(0)=\frac{m(n+1)+1}{2}$. Hence $\left|v_{f}(1)-v_{f}(0)\right|=1$ and $\left|e_{f}(1)-e_{f}(0)\right|=1$. Therefore the graph $J_{n, m}$ is product cordial.

This completes the proof.

Figure 3 below illustrates the product cordial labeling of graph $J_{2,5}$.

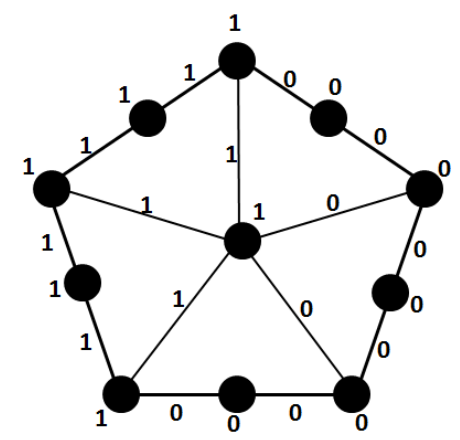

Figure 3. Product cordial labeling of $J_{2,5}$

In Theorem 2.2, the graph $J_{n, m}$ is product cordial labeling for $n \geq 2, m \geq 3, m$ is odd and $n$ is even. We have tried to find the product cordial labeling of $J_{n, m}$ for all values of $m$ and $n$ but so far without success. So we pose the following open problem.

Problem 1. Determine product cordial labeling of the Jahangir graph $J_{n, m}$ for all $m$ and $n$. 
Theorem 2.3. The Jahangir graph $J_{n, m}, n \geq 2, m \geq 3$ is total product cordial.

Proof. Let $J_{n, m}, n \geq 2, m \geq 3$ be a Jahangir graph with the vertex set $V\left(J_{n, m}\right)=\{v\} \cup\left\{v_{i}\right.$ : $1 \leq i \leq m n\}$ and the edge set $E\left(J_{n, m}\right)=\left\{v_{i} v_{i+1}: 1 \leq i \leq m n-1\right\} \cup\left\{v_{m n} v_{1}\right\} \cup\left\{v v_{n(i-1)+1}\right.$ : $1 \leq i \leq m\}$. Clearly that $\left|V\left(J_{n, m}\right)\right|=m n+1$ and $\left|E\left(J_{n, m}\right)\right|=m(n+1)$.

To show that $J_{n, m}$ is total product cordial, define a vertex labeling $f: V\left(J_{n, m}\right) \rightarrow\{0,1\}$ in the following way:

Case 1: $m$ and $n$ are odd.

$$
\begin{gathered}
f(v)=1, f\left(v_{m n-1}\right)=1 \\
f\left(v_{i}\right)= \begin{cases}1, & \text { if } 1 \leq i \leq \frac{n m-1}{2} \\
0, & \text { if } \frac{n m+1}{2} \leq i \leq m n, i \neq m n-1\end{cases}
\end{gathered}
$$

We have $\left|v_{f}(1)\right|=\left\lceil\frac{m n+2}{2}\right\rceil,\left|v_{f}(0)\right|=\left\lfloor\frac{m n}{2}\right\rfloor,\left|e_{f}(1)\right|=\frac{m(n+1)-2}{2},\left|e_{f}(0)\right|=\frac{m(n+1)+2}{2}$. It is easy to see that $\left|\left(v_{f}(1)+e_{f}(1)\right)-\left(v_{f}(0)+e_{f}(0)\right)\right| \leq 1$. Hence the graph $J_{n, m}$ is total product cordial.

Case 2: $m$ and $n$ are not odd.

$$
\begin{gathered}
f(v)=1 \\
f\left(v_{i}\right)= \begin{cases}1, & \text { if } 1 \leq i \leq \frac{n m}{2} \\
0, & \text { if } \frac{n m+2}{2} \leq i \leq m n\end{cases}
\end{gathered}
$$

We have $\left|v_{f}(1)\right|=\frac{m n+2}{2},\left|v_{f}(0)\right|=\frac{m n}{2},\left|e_{f}(1)\right|=\left\lfloor\frac{m(n+1)-1}{2}\right\rfloor,\left|e_{f}(0)\right|=\left\lceil\frac{m(n+1)+1}{2}\right\rceil$. It is easy to see that $\left|\left(v_{f}(1)+e_{f}(1)\right)-\left(v_{f}(0)+e_{f}(0)\right)\right| \leq 1$. Hence the graph $J_{n, m}$ is total product cordial.

This completes the proof.

Figure 4 shows the total product cordial labeling of graph $J_{4,5}$.

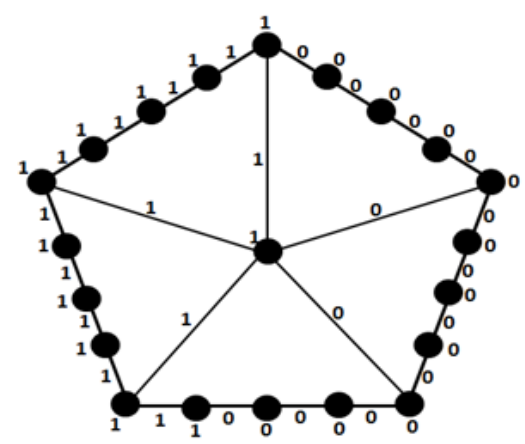

Figure 4. Total product cordial labeling of graph $J_{4,5}$ 
In $[15,16]$, Vaidya and Barasara introduced an edge product cordial labeling and a total edge product cordial labeling of graph $G$. Thus, we propose the following problem.

Problem 2. Determine edge product cordial labeling and total edge product cordial labeling of the Jahangir graph $J_{n, m}$ for $n, m \geq 2$.

Acknowledgement The authors would like to thank the referee for his/her valuable comments which improved the paper.

[1] K. Ali, E.T. Baskoro and I. Tomescu, On the Ramsey number of paths and Jahangir graph $J_{3, m}$, The 3rd International Conference on 21st Century Mathematics, GC University Lahore, Pakistan, 2007.

[2] I. Cahit, Cordial graphs: a weaker version of graceful and harmonious graphs, Ars Combin., 23(1987) 201-207.

[3] J.A. Gallian, A dynamic survey of graph labeling, The Electronic Journal of Combinatorics 5, vol. 18, p. DS6, 2011.

[4] Z.B. Gao, G.Y. Sun, Y.N. Zhang, Y. Meng and G.C. Lau, Product cordial and total product cordial labelings of $P_{n+1}^{m}$, Journal of Discrete Mathematis, Volume 2015, Article ID 512696, 6 pages.

[5] H. Kwong, S.M. Lee and H.K. Ng, On product cordial index sets and friendly index sets of 2-regular graphs and generalized wheels, Acta Math. Sinica, English Series, 28(4)(2012), 661-674.

[6] H. Kwong, S.M. Lee and H.K. Ng, On product cordial index sets of cylinders, Congressus Numerantium, 206(2010), 139-150.

[7] D. A. Mojdeh and A. N. Ghameshlou domination in Jahangir graph $J_{2, m}$ Int. J. Contemp. Math. Sciences, 2(24)(2007), 1193-1199.

[8] M. Sundaram, R. Ponraj and S. Somasundram, Prime cordial labeling of graphs, Journal of Indian Academy of Mathematics, 27(2)(2005), 373-390.

[9] M. Sundaram, R. Ponraj and S. Somasundram, Product cordial labeling of graphs, Bulletin of Pure and Applied Science (Mathematics and Statistics), 23(2004), 155-163.

[10] M. Sundaram, R. Ponraj and S. Somasundram, Total product cordial labeling of graphs, Bulletin of Pure and Applied Science (Mathematics and Statistics), 25(1)(2006), 199-203.

[11] M. Sundaram, R. Ponraj and S. Somasundram, Some results on total product cordial labeling of graphs, Indian Academy of Mathematics, 28(2)(2006), 309-320. 
[12] S.K. Vaidya and P.L. Vihol, Prime cordial labeling for some cycle related graphs, International Journal of Open Problems in Computer Science and Mathematics, 3(5)(2010), 223232 .

[13] S.K. Vaidya and P.L. Vihol, Prime cordial labeling for some graphs, Modern Applied Sciences, 4(8)(2010), 119-126.

[14] S.K. Vaidya and N.H. Shah, Some new results on prime cordial labeling, ISRN Combinatorics, Volume 2014, Article ID 607018, 9 pages.

[15] S.K. Vaidya and C.M. Barasara, Edge product cordial labeling of graphs, Journal of Mathematical and Computational Science, 2(5)(2012), 1436-1450.

[16] S.K. Vaidya and C.M. Barasara, Total edge product cordial labeling of graphs, Malaya Journal of Matematik, 3(1)(2013), 55-63.

[17] A. Tout, A.N. Dabboucy and K. Howalla, Prime labeling of graphs, National Academy Science Letter, 11(1982), 365-368.

[18] D.B. West, Introduction to Graph Theory, 2nd Edition, Prentice Hall, USA, 2001. 